\title{
Molecular cloning and nucleotide sequence of a gene for alkaline cellulase from Bacillus sp. KSM-635
}

\author{
KatsuYa Ozaki, Shitsuw Shikata, Shuji Kawai, Susumu Ito* and Kikuhiko OKamoto
}

Tochigi Research Laboratories of the Kao Corporation, 2606 Akabane, Ichikai, Haga, Tochigi 321-34, Japan

(Received 12 December 1989; revised 13 February 1990; accepted 5 March 1990)

\begin{abstract}
A gene for alkaline cellulase from the alkalophilic Bacillus sp. KSM-635 was cloned into the HindIII site of pBR322 and expressed in Escherichia coli HB101. Although the recombinant plasmid contained two HindIII inserts of $2.6 \mathrm{~kb}$ and $4.0 \mathrm{~kb}$, the inserts were found to be contiguous in the Bacillus genome by hybridization analysis. Nucleotide sequences of a $2.4 \mathrm{~kb}$ region which was indispensable for the production of cellulase, and the flanking, $1.1 \mathrm{~kb}$ region, were determined. There was an open reading frame (ORF) of $2823 \mathrm{bp}$ in the $3498 \mathrm{bp}$ sequence determined, which encoded 941 amino acid residues. Two putative ribosome-binding sites and a $\sigma^{43}$-type, promoter-like sequence were found upstream from an initiation codon in the ORF. The deduced amino-terminal sequence resembles the signal peptide of extracellular proteins. A region of amino acids, 249 to 568 , of the deduced amino acid sequence of the cellulase from this organism is homologous with those of alkaline and neutral enzymes of other micro-organisms, but nine amino acid residues were found to be conserved only in the alkaline enzymes.
\end{abstract}

\section{Introduction}

Members of the genus Bacillus produce many kinds of extracellular hydrolytic enzymes, including cellulases (Priest, 1977). The cellulolytic enzymes of Bacillus have recently been the focus of much attention because of their potential use in the bioconversion of agricultural wastes into useful products (Ryu \& Mandels, 1980) and in laundry detergents (Kawai et al., 1988; Ito et al., 1989). For the latter purpose, the enzyme must act at high $\mathrm{pH}$, because of the alkalinity of laundry detergents. Production of such alkaline cellulases has been reported for alkalophilic Bacillus strains (Horikoshi et al., 1984; Fukumori et al., 1985) and for neutrophilic Bacillus sp. KSM-522 (Kawai et al., 1988).

Recently, alkalophilic Bacillus sp. KSM-635, isolated in this laboratory, was also found to produce an alkaline cellulase (endo-1,4- $\beta$-glucanase, $1,4-\beta$-D-glucan 4glucanohydrolase, EC 3.2.1.4) in quantity (Ito et al., 1989). In a study of this alkaline cellulase, it was found that the molecular mass of the enzyme as judged by gel filtration, varied from $100 \mathrm{kDa}$ to $600 \mathrm{kDa}$ depending upon culture conditions. This variation may indicate that the cellulase forms complexes, as reported for several

Abbreviation: ORF, open reading frame.

The nucleotide sequence data reported in this paper have been submitted to GenBank and have been assigned the accession number M27420. other bacterial cellulases (Yoshikawa et al., 1974; Ait et al., 1979; Wood et al., 1982; Horikoshi et al., 1984; Langsford et al., 1984; Schellhorn \& Forsberg, 1984).

In order to characterize such multiple forms of the alkaline cellulase, further enzymic and genetic analyses have been carried out. This report describes the molecular cloning of a gene for alkaline cellulase from Bacillus sp. KSM-635 and the determination of its nucleotide sequence. Furthermore, a deduced amino acid sequence of the alkaline cellulase from this microorganism is compared with those of other alkaline and neutral cellulases, with respect to their optimum pHs for enzymic activity.

\section{Methods}

Bacterial strains, plasmids and bacteriophages. Bacillus sp. KSM-635, isolated from a soil sample (Ito et al., 1989), was used as the source of a gene for alkaline cellulase. Escherichia coli $\mathrm{HB} 101\left(\mathrm{~F}^{-}\right.$hsdS20 recA13 ara-14 proA2 lacY1 galK2 rpsL20 xyl-5 mtl-1 supE44 leuB6 thi-l) and $E$. coli JM109 (recAl $\triangle$ (lac-pro) end Al gyrA96 thi-l hsdR17 supE44 relAl $F^{\prime}$ traD36 proAB lacI ${ }^{9} Z \Delta M 15$ ) were used as the hosts. Plasmid pBR322 and bacteriophages $\mathrm{M} 13 \mathrm{mp} 18$ and $\mathrm{M} 13 \mathrm{mp} 19$ were used for cloning and nucleotide sequencing.

Culture media. E. coli strains were grown in LB broth, YT broth or $2 \times$ YT broth (Miller, 1972). MYG broth $[1.5 \%$ meat extract (LABLEMCO powder, Oxoid) $/ 0.5 \%$ yeast extract (Difco) $/ 0.1 \% \mathrm{KH}_{2} \mathrm{PO}_{4} /$ $1.0 \%$ glucose $/ 0.5 \% \mathrm{Na}_{2} \mathrm{CO}_{3}$; by weight] was used for the propagation 
of Bacillus sp. KSM-635. Solidified media contained $1.5 \%$ or $0.8 \%$ (w/v) Bacto agar (Difco).

Preparation of DNA. Bacillus sp. KSM-635 was grown in MYG broth at $30^{\circ} \mathrm{C}$ for $2 \mathrm{~d}$, with shaking, and harvested by centrifugation. The chromosomal DNA was prepared as described by Saito \& Miura (1963). Plasmid DNA and the replicative form of M13 bacteriophage DNA were isolated by the alkaline extraction procedure (Birnboim \& Doly, 1979). Covalently closed circular DNA was purified by equilibrium density gradient centrifugation on $\mathrm{CsCl} /$ ethidium bromide.

Construction of recombinant plasmids. The chromosomal DNA from Bacillus sp. KSM-635 and pBR322 DNA were digested with HindIII and ligated by $\mathrm{T}_{4}$ DNA ligase (Boehringer Mannheim) overnight at $16{ }^{\circ} \mathrm{C}$. The ligated molecules were used for transformation of $E$. coli HB101 by the method of Mandels \& Higa (1970).

Detection of cellulase-positive transformants. Transformed cells were selected by growth on LB agar plates that contained $50 \mu \mathrm{g}$ ampicillin $\mathrm{ml}^{-1}$ (Sigma) and carboxymethylcellulose $\left(2.0 \%\right.$ w/v) at $37^{\circ} \mathrm{C}$. Production of cellulase by the drug-resistant colonies was visualized by staining the agar plates with Congo red (Teather \& Wood, 1982).

Assay of cellulase activity. E. coli carrying the recombinant plasmid was grown on LB broth that contained ampicillin $\left(50 \mu \mathrm{g} \mathrm{ml}^{-1}\right)$ at $37^{\circ} \mathrm{C}$ for $24 \mathrm{~h}$. A cell-free extract was prepared by sonication. Cellulase activity expressed in $E$. coli was assayed as described previously (Ito $e t$ al., 1989).

Nick-translation and hybridization analysis of DNA digests. A ${ }^{32} \mathrm{P}-$ labelled DNA probe was prepared using a nick-translation kit (Takara Syuzo) and $\left[\alpha^{-32} \mathrm{P}\right] \mathrm{dCTP}\left(410 \mathrm{Ci} \mathrm{mmol}^{-1}, 15.2 \mathrm{TBq} \mathrm{mmol}^{-1}\right.$; Amersham; Rigby et al., 1977) and then purified by gel filtration on Sephadex G-50. DNA digests, subjected to electrophoresis on agarose gel, were denatured by treatment with $0.2 \mathrm{M}-\mathrm{NaOH} / 0.5 \mathrm{M}-\mathrm{NaCl}$ and then transferred electrically to a nylon membrane (Zeta-Probe Blotting Membrane, Bio-Rad). The DNA digests on the membrane were hybridized with the DNA probe, according to the manufacturer's directions, and the resulting radioactive hybrids were exposed to $\mathrm{X}$-ray film (New RX, Fuji).

Nucleotide sequencing. The nucleotide sequence was determined by the dideoxy method of Sanger et al. (1977), using an M13 sequencing kit (Takara Syuzo) and $\left[\alpha^{-32} \mathrm{P}\right] \mathrm{dCTP}$. The template DNA was prepared from M13mp18 or M13mp19 phage vector, as described by Messing (1983).

Preparation of antiserum. Crude alkaline cellulase from Bacillus sp. KSM-635 was prepared as described previously (Ito et al., 1989). The preparation was purified by column chromatography on DEAEToyopearl 650S (Tosoh) and Bio-Gel A-0.5 m (Bio-Rad). The purified enzyme ( $1 \mathrm{mg}$ ) was mixed with an equal volume of incomplete adjuvant and then injected subcutaneously into a white rabbit at 2- to 3-week intervals. The antiserum formed was used for double-immunodiffusion analysis.

\section{Results}

\section{Cloning of a gene for cellulase}

After screening for ampicillin-resistant and cellulasepositive transformants of $E$. coli $\mathrm{HB} 101$, eight clones were selected. All plasmids in the clones had two or more inserts in the HindIII site of pBR322. The insert of $4.0 \mathrm{~kb}$ was observed in all the plasmids. Additionally, seven plasmids had a $2.6 \mathrm{~kb}$ insert. The smallest plasmid, named $\mathrm{pBC} 100$, contained inserts of $4.0 \mathrm{~kb}$ and $2.6 \mathrm{~kb}$ as HindIII fragments, and its restriction map is shown in Fig. 1.

pBC100-encoded cellulase was active over a range of $\mathrm{pH}$ values from 5.0 to 11.0 and exhibited maximum activity at $\mathrm{pH} 9 \cdot 5$. The $\mathrm{pH}$-activity curve of the enzyme coincided with that of the alkaline cellulase from Bacillus sp. KSM-635 (data not shown).

Double-immunodiffusion was done using the antiserum prepared against the cellulase purified from Bacillus sp. KSM-635. The cellulase from $E$. coli HB101 carrying $\mathrm{pBC} 100$ gave a single precipitin line which fused with that for the authentic cellulase from Bacillus sp. KSM-635 (data not shown).

\section{Hybridization analysis of HindIII inserts of pBC100}

In order to confirm that the $4.0 \mathrm{~kb}$ DNA insert was directly adjacent to the $2.6 \mathrm{~kb}$ insert, hybridization analysis was done using a ${ }^{32} \mathrm{P}$-labelled probe prepared from the $1.1 \mathrm{~kb} \mathrm{XbaI}$ fragment in $\mathrm{pBCl} 100$ (the open box in Fig. 1). As shown in Fig. 2, XbaI digests of Bacillus DNA contained a $1.1 \mathrm{~kb}$ fragment that hybridized with the labelled $X b a I 1.1 \mathrm{~kb}$ probe. Both the $2.6 \mathrm{~kb}$ and $4.0 \mathrm{~kb}$ fragments in HindIII digests of the Bacillus DNA also hybridized with the probe. Thus, the $2.6 \mathrm{~kb}$ and $4.0 \mathrm{~kb}$ HindIII inserts of $\mathrm{pBC} 100$ were proved to be contiguous in the Bacillus genome.

\section{Localization of the cellulase gene}

Sub-cloning analysis was done to locate the cellulase gene in the HindIII inserts of pBC100. The $4.0 \mathrm{~kb}$ insert was sufficient for the production of cellulase, and it was successfully trimmed down by Bal31 nuclease to a $2.4 \mathrm{~kb}$ fragment (the thickest line in Fig. 1), without loss of production of the enzyme. However, the $2.4 \mathrm{~kb}$ fragment was too small to encode the Bacillus sp. KSM-635 cellulase with a molecular mass of $100 \mathrm{kDa}$ or more (Ito et al., 1989). This result proves that the $2.4 \mathrm{~kb}$ fragment encodes only the region of the Bacillus cellulase that is essential for its activity.

\section{Nucleotide sequence analysis}

The nucleotide sequence of the $2.4 \mathrm{~kb}$ fragment essential for expression of cellulase activity, and that of its flanking region $(1.1 \mathrm{~kb})$, in the $2.6 \mathrm{~kb}$ HindIII insert were determined. The $3498 \mathrm{bp}$ nucleotide sequence that was determined is shown in Fig. 3. Only one open reading frame (ORF), encoding a protein of approximately $105 \mathrm{kDa}$, was identified in the sequence. The ORF began 


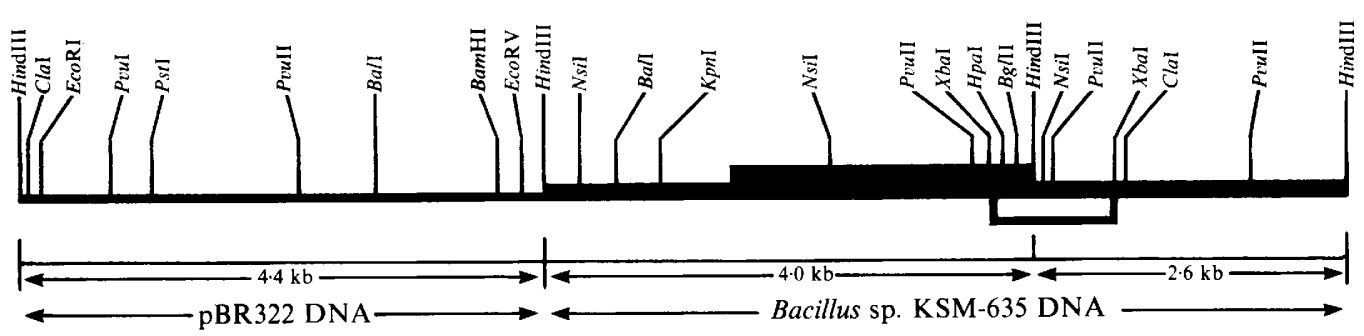

Fig. 1. Restriction map of plasmid pBC100. The middle and thickest lines indicate cloned HindIII fragments from Bacillus sp. KSM635. The thickest line indicates a region that is essential for expression of cellulase activity. The open box under the map shows the $1.1 \mathrm{~kb} X b a$ I fragment used for preparation of the ${ }^{32} \mathrm{P}$-labelled DNA probe for the hybridization analysis of cloned fragments.

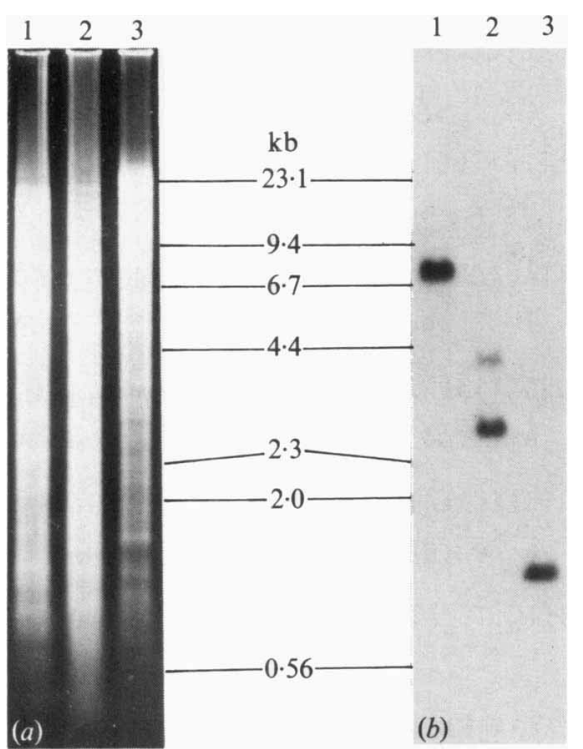

Fig. 2. Hybridization analysis of the HindIII inserts of pBC100. DNA from Bacillus sp. KSM-635, digested with EcoRI (lane 1), HindIII (lane 2) or $X b a I$ (lane 3), was electrophoresed on a $0.8 \%$ agarose gel and then transferred onto a nylon membrane. The DNA digests on the membrane were hybridized with the ${ }^{32} \mathrm{P}$-labelled $1 \cdot 1 \mathrm{~kb}$ XbaI fragment of pBC100. (a) Results of agarose gel electrophoresis of digests of KSM635 DNA. (b) Autoradiograms of digests of KSM-635 DNA hybridized with labelled $X b a$ I probe.

at nucleotide 1 (ATG) in the $2.4 \mathrm{~kb}$ fragment and ended at nucleotide 2824 (TAA) in the $2.6 \mathrm{~kb}$ insert. A HindIII restriction site at the $3^{\prime}$ end of the $2.4 \mathrm{~kb}$ fragment was observed at nucleotide 1747 . Upstream from the initiation codon of the ORF, there were two putative ribosome-binding sites (SD1 and SD2), each of which was highly complementary to the $3^{\prime}$ end of 16 S ribosomal RNA (rRNA) from Bacillus subtilis (Hager \& Rabinowitz, 1985). The SD1 site occurred at nucleotide -65 (AAGGAGG) and the SD2 site occurred at nucleotide -10 (GGAGGT). The sequence from nucleotide -134 to -106 was similar to the consensus sequence of the $\sigma^{43}$-type promoter of $B$. subtilis (Moran $e t$ al., 1982). This sequence consisted of TAGACG as the -35 region and TATTAT as the -10 region. A complete inverted-repeat sequence was found downstream from the stop codon of the ORF (nucleotides 2837 to 2861 ).

The deduced amino acid sequence (941 residues), shown under the nucleotide sequence in Fig. 3, contained a short hydrophilic region from amino acids 1 to 9, followed by a hydrophobic region from amino acids 10 to 29. The hydrophilic region was slightly basic because of the presence of the three lysine residues. The hydrophilic-hydrophobic sequence is similar to the signal peptide of extracellular proteins from the genus Bacillus (Mezes \& Lampen, 1985).

Homology of the amino acid sequence to those of other glucanases

The deduced amino acid sequence of the alkaline cellulase from Bacillus sp. KSM-635 was compared with those of other cellulases (endo-1,4- $\beta$-glucanases). The sequence, from amino acids 229 to 941 , had high homology (approximately $72 \%$ ) with that of alkaline cellulase from Bacillus sp. strain 1139 (Fukumori et al., $1986 a$ ). Additionally, the region of amino acids 249 to 568 of the cellulase from Bacillus sp. KSM-635 was also homologous $(38-40 \%)$ with sequences of two alkaline cellulases from Bacillus sp. N-4 (Fukumori et al., 1986b) and four neutral cellulases from three strains of Bacillus subtilis (MacKay et al., 1986; Robson \& Chambliss, 1987; Nakamura et al., 1987) and from Clostridium acetobutylicum P262 (Zappe et al., 1988). Alignment of these homologous amino acid sequences is shown in Fig. 4. In these regions, 90 amino acid residues of the cellulase from Bacillus sp. KSM-635 were found to correspond with those of all the cellulases mentioned above. 


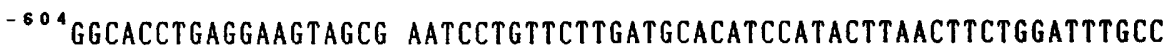

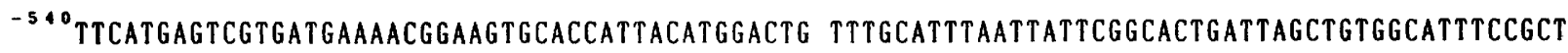

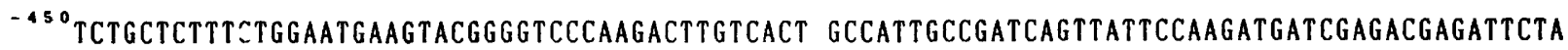

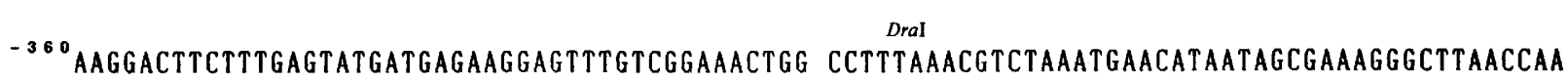
- 270 OAATATGAATTGAACCCACATAAATTTGTGGGTTTTTATTAATCL

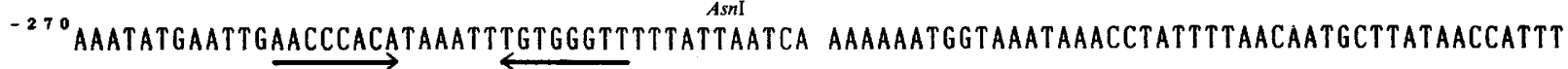

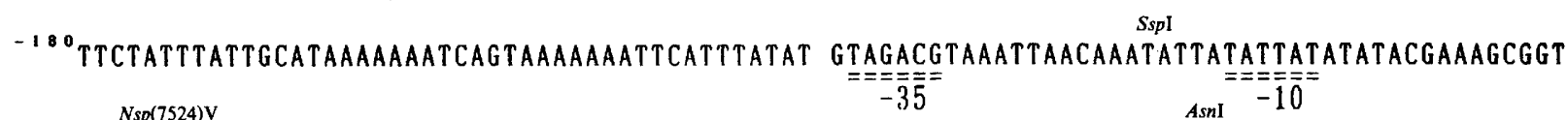

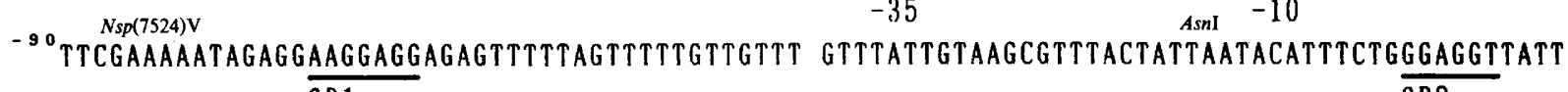
SD1 'ATGAAAATAAAGCAAATTAAACAATCTTTATCTTTGCTTTTAATC ATCACACTCATTATGTCACTATTTGTTCCTATGgCTTCAgCAAAC

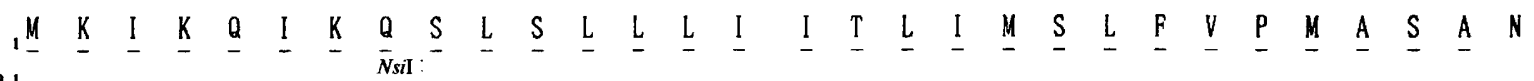

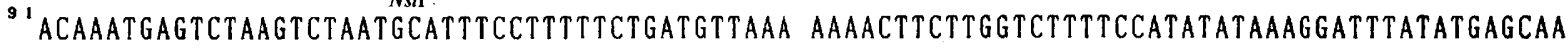

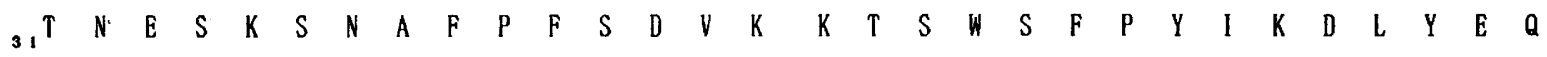
181 GaAgTTATTACAGgaACATCTGCAACAACGTTCTCTCCAACAgAT TCCGTTACTCGTGCACAATTTACAgTgaTgCTTACCCGTGgTCTT

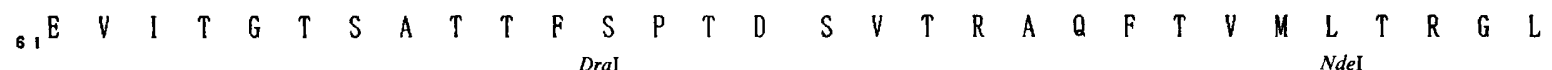
271 GGACTAGAAGCATCTTCTAAAGATTACCCTTTTAAAGATCGTAAA AACTGGGCTTACAAAGAAATTCAAGCTGCATATGAAGCTGGAATT

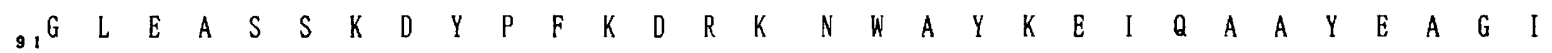
${ }^{36}$ GTAACTGGGAAACAAACGGTGAATTTGCACCAAATGAAAACATT ACTCGTGAACAAATGGCTGCTATGGCCGTACGTGCTTATGAATAC 12,V $T$ T G 45 ITAGAAAATGAGCTATCTTTACCAGAAGAGCAAAGAGAATATAAT GACTCTTCTTCTATTTCAACCTTTGCTCAAGATGCTGTTCAAAAA

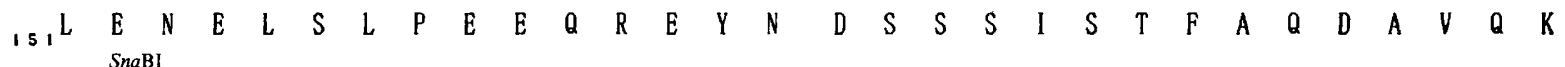

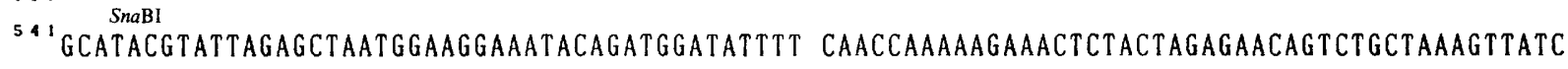
${ }_{181} A^{4}$ Y V V L L E

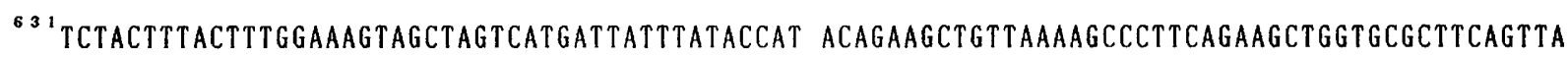

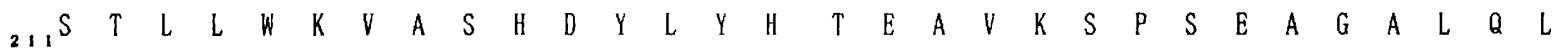

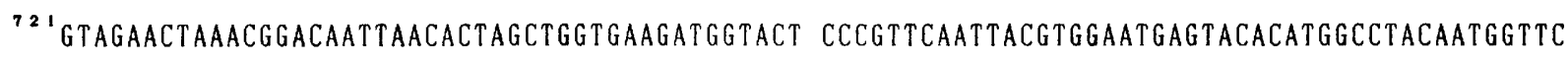

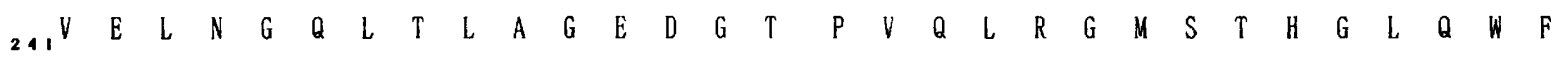

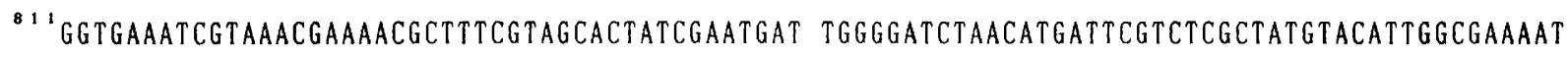

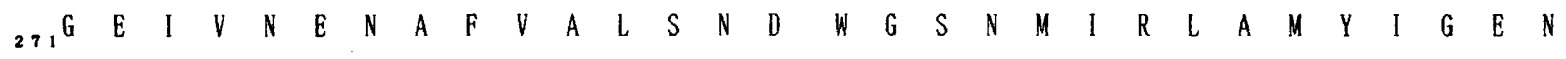

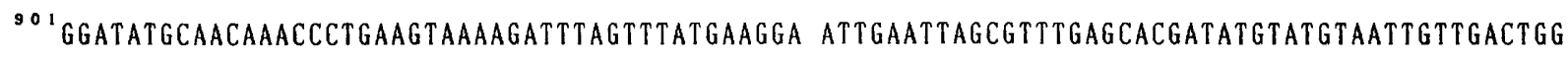

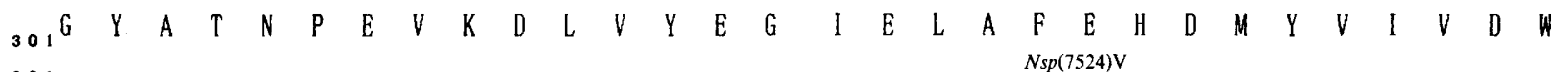

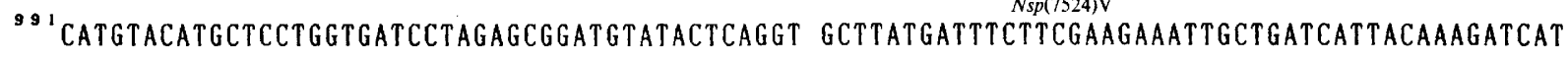

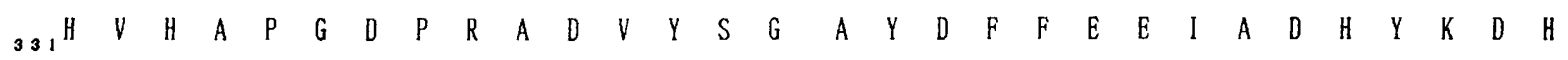

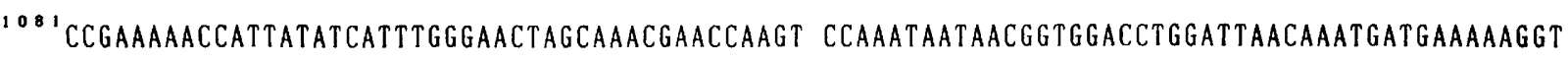

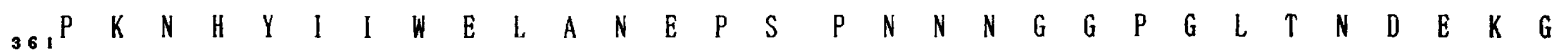
$\because 71$ TGgGaAgCTGTAAAAGAATATGCAGAGCCAATCGTTGAAATGTTG CGTGAAAAAGgTGACAACATGATTTTAGTTGGAAATCCTAACTGG 39,W 1261 AgCCAACGTCCTGACTTATCAGCTGACAACCCAATtgatgCagaA AaTATCATGTATTCTGTTCACTTCTACACAGgCTCACATGgCGCT

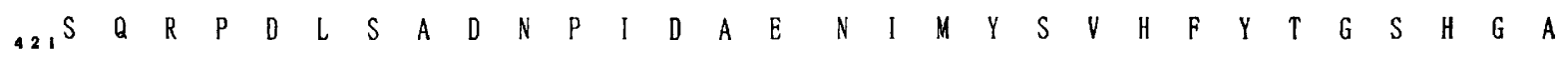


135 :TCTCACATTGGTTACCCTGAAGGAACACCAAGCTCTGAACGTTCT AATGTTATGGCTAACGTTCGTTATGCTCTAGAC

(1) ${ }_{45} 1^{S}$ S

14'GTGTTTGCGACAGAGTGGgGTACGAGTCAAGCGAATGGAGATGGA GGACCTTATTTTGATGAAGCTGATGTTTGGCTTAATTTCTTAAAC

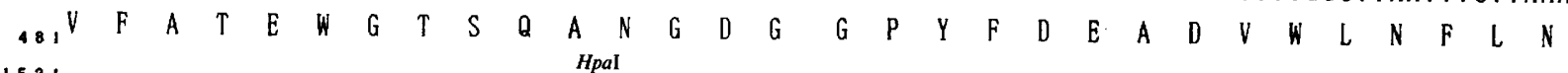
153 s AAACATAACATTAGCTGgGCAAACTgGTCGTTAACGAACAAAAAT GAGATTTCTGGAGCATTTACACCTTTTGAGCTTGgTAGAACAGAT

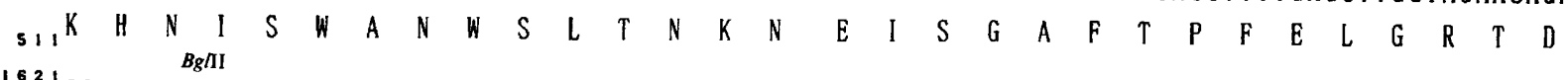

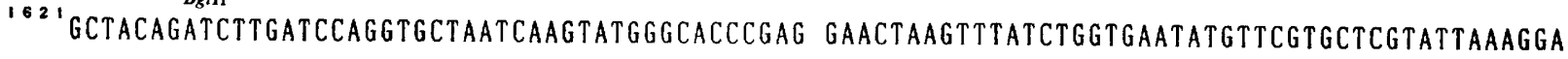
$\begin{array}{rlllllllllllllllllllllllllllllllll}5,1 & T & D & L & D & P & G & A & N & Q & V & W & A & P & E & E & L & S & L & S & G & E & Y & V & R & A & R & I & K & G\end{array}$ 17 'ATTGAGTATACACCTATCGACCGCACAAAATTCACAAAGCTTGTT TGGgaTTTTAACGATGGAACAACACAAGgaTTCCAAGTTAATGGA

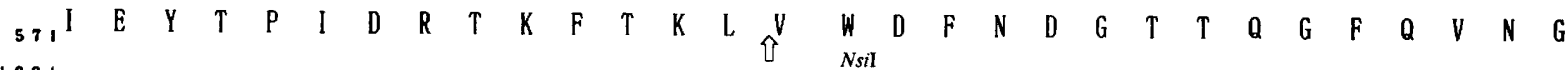
$1801 G A C A G C C C T A A C A A A G A A A G C A T T A C T T T A A G T A A T A A T A A T G A T$ GCATTACAAATTGAAGgaTTAAATGTAAGTAATGATATTTCTGAA $\begin{array}{lllllllllllllllllllllllllllllllll}60 & D & S & P & N & K & E & S & I & T & L & S & N & N & N & D & A & L & Q & I & E & G & L & N & V & S & N & D & I & S & E\end{array}$

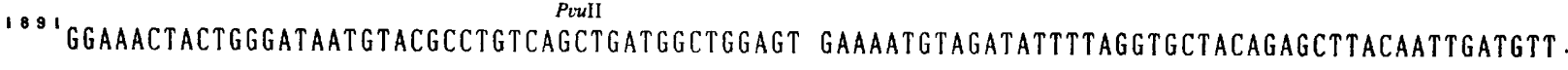

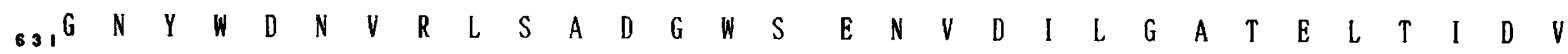

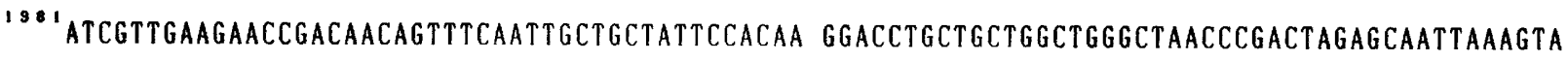

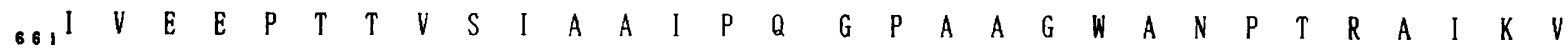
Nsp(7524)V

'ACTGAAGACGATTTCGAATCTTTCGgAGATGgATACAAAGCTCTC GTAACTATTACTTCTGAAGATTCACCTTCACTTGAAACCATTGCA

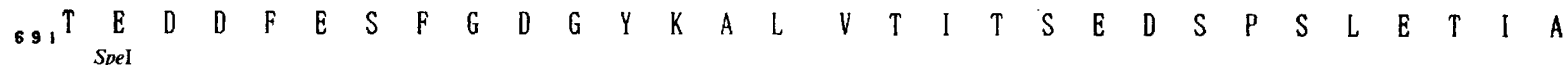
2161 SpeI

2161 ACTAGTCCTGAagACAATACAATGAGCAATATCATTCTATTTGTA GgTACTGAAGATGCAGATGTTATTTCTTTAGATAATATCACGgTT

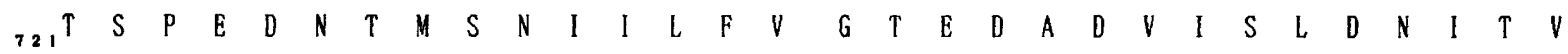

2251 TCTGGTACTGAGATTGAAATTGAAGTTATTCACGATGAAAAAGGA ACAGCAACACTTCCTTCTACTTTTGAAGATGGAACTCGCCAAGGC

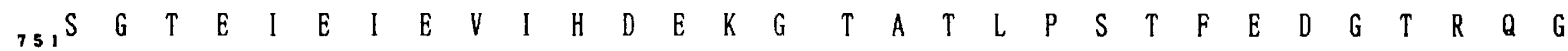

234 'TGGgATTGGCATACAGAATCAGgagTTAAGACAGCTCTTACAATT GAAGAAGCTAATGGATCTAACGCTCTTTCATGGGAATATGCGTAT $\begin{array}{rllllllllllllllllllllllllllllllll}7.1 & D & W & H & T & E & S & G & V & K & T & A & L & T & I & E & E & A & N & G & S & N & A & L & S & W & E & Y & A & Y\end{array}$ 2431 CCTGAAGTAAAACCAAGTGATGGTTGGgCTACTGCTCCTCGTCTA GACTTCTGGAAAGACGAACTAGTTCGTGGCACAAGCGACTATATT

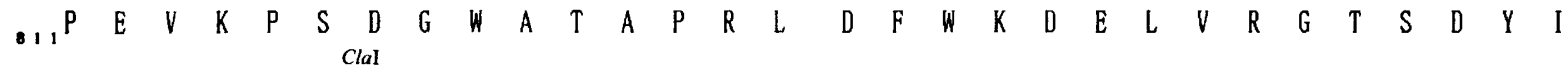
2521 AgTTTTGACTTTTACATCGATGCAGTTCGTGCTTCTGAAGgTGCT ATATCAATTAACGCCGTTTTCCAACCACCTGCAAACGgGTATTGG $\begin{array}{lllllllllllllllllllllllllllllllll}{ }_{84} & S & F & D & F & Y & I & D & A & V & R & A & S & E & G & A & I & S & I & N & A & V & F & Q & P & P & A & N & G & Y & W\end{array}$

261 'CAAGAAGTTCCAACTACATTTGAAATTGATTTAACAGAGCTTGAT TCTGCAACTGTAACTTCTGATgAGTTGTATCATTATGAagTAAAA \begin{tabular}{rlllllllllllllllllllllllllllllll}
\hline $7 I^{\prime}$ & $E$ & $V$ & $P$ & $T$ & $T$ & $F$ & $E$ & $I$ & $D$ & $L$ & $T$ & $E$ & $L$ & $D$ & $S$ & $A$ & $T$ & $V$ & $T$ & $S$ & $D$ & $E$ & $L$ & $Y$ & $H$ & $Y$ & $E$ & $V$ & $Y$
\end{tabular} 2701 ATTAACATTAGAGACATTGAGgCTATTACAGACGATACAGAGCTT CGTAACTTATTACTAATCTTTGCTGATGAAGACAGTGATTTTGCT 90 I $N$ N

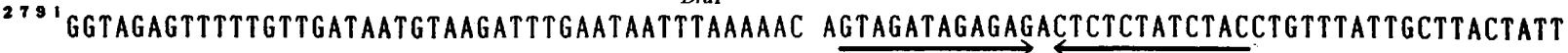
$9, G \quad R \quad V \quad F \quad V \quad D \quad N \quad V \quad R \quad F \quad E$ *

$2: 1$ CGTCTTCCACTTTT

Fig. 3. Nucleotide sequence of the cellulase gene and deduced amino acid sequence. The nucleotide sequence of the coding strand is given from $5^{\prime}$ to $3^{\prime}$, and the deduced amino acid sequence is shown under the nucleotide sequence. Numbering of both nucleotides and amino acids starts with the beginning of the coding sequence. Putative -35 and -10 regions of the promoter are labelled with double dashed lines. Two putative ribosome-binding sites (SD1 and SD2) are underlined. Horizontal arrows indicate terminator-like, invertedrepeat sequences. A putative signal sequence is indicated by a broken line under the amino acid sequence. A vertical open arrow indicates the $3^{\prime}$ end of the $2.4 \mathrm{~kb}$ fragment that is essential for expression of cellulase activity. 


Ba KSM-635
Ba 1139
Ba N-4(1)
Ba N-4(2)
Bs IFO3034
Bs PAP115
Bs DLG
Ca P262

Ba KSM-635

Ba 1139

Ba N-4(1)

$\mathrm{Ba} \mathrm{N}-4(2)$

Bs IFO3034

Bs PAP115

Bs DLG

Ca P262

Ba KSM-635

Ba 1139

Ba N-4(1)

Ba N-4(2)

Bs IFO3034

Bs PAP115

Bs DLG

Ca P262

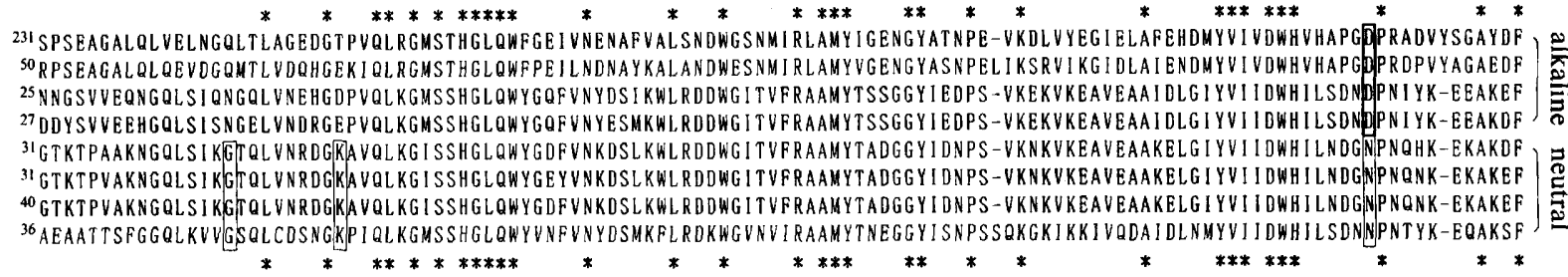

\section{$* \quad * \quad * * * * * \quad * * \quad * \quad * * * \quad * \quad * \quad * \quad * * \quad * * * \quad * * \quad * \quad * * * * * *$}

${ }^{350} \mathrm{FEEIADHYKDHPKNHYII} \mathrm{WELANEPSPNNNGGPGLTNDEKGWE-AVKEYAEPIVEMLREKG---DNMILVGNPNWSQRPDLSADNPIDAENIMYSVHFYTGSHGASHIGYPEGTPSSERS}$ $170 \mathrm{FRDIAALYPNNP}$-- - HIIYELANEPSSNNNGGAGI PNNEEGWN-AVKEYADPIVEMLRDSGNADDNIIIVGSPNWSQRPDLAADNPI DDHHTMYTVHFYTGSHAASTESYPPETPNSERG

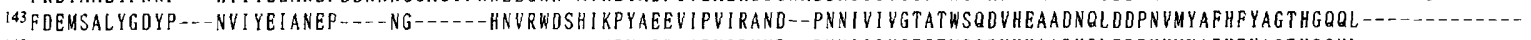

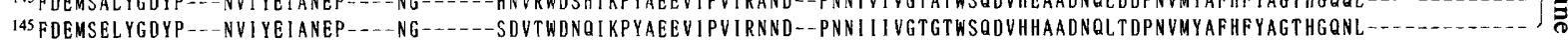

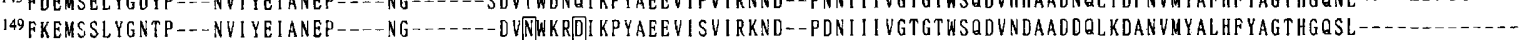

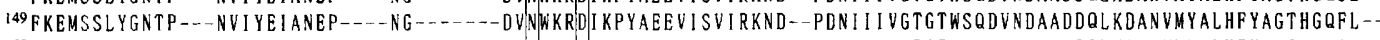

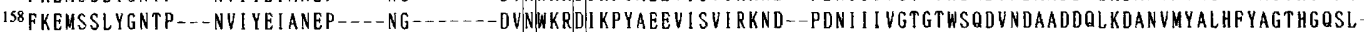
I5S FQEMAEEYGKYS---NVIYEICNEP----NGG-----T NWANDIIKPYANYIIPAIRAID--PNNIIIVGTSTWSQDVDIAADNPLRYSNIMYTCHFYAGTHTQSL

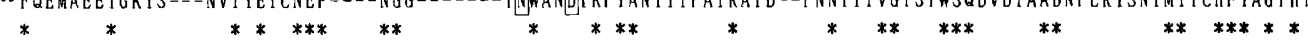
$* * * * * * * * * * * * * * * * * * * * * * * * * * *$

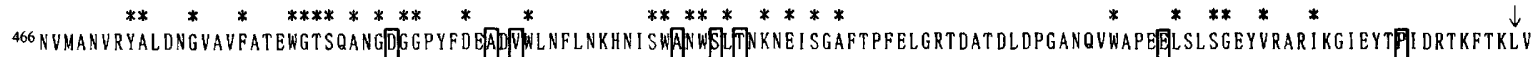

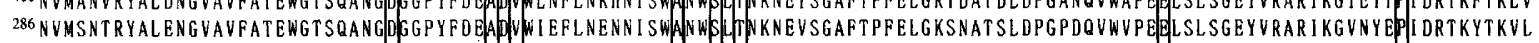

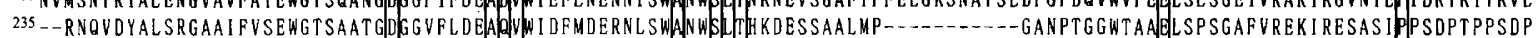

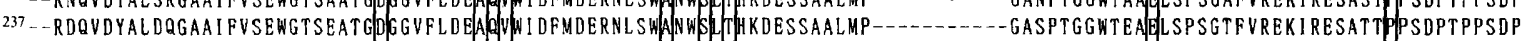

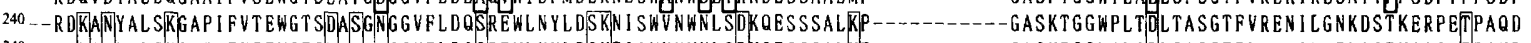

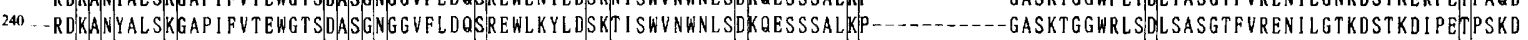

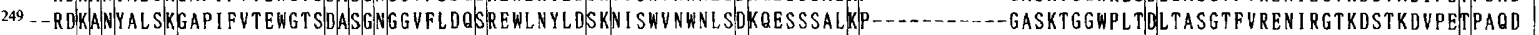

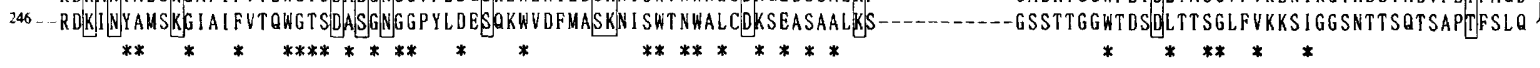

Fig. 4. Comparison of the amino acid sequence of alkaline cellulase from Bacillus sp. KSM-635 with those of alkaline and neutral enzymes from other micro-organisms. Amino acid residues conserved in all the cellulases are indicated by asterisks. Amino acid residues conserved only in alkaline cellulases or in neutral cellulases are boxed with bold or thin lines, respectively. The vertical arrow indicates the carboxy-terminus (Leu-584) of the truncated cellulase encoded by the $2.4 \mathrm{~kb}$ fragment. Ba, Bacillus sp. (alkalophilic); Bs, Bacillus subtilis; Ca, Clostridium acetobutylicum.

Furthermore, nine amino acid residues were found to be conserved only in the alkaline cellulases, and 18 amino acid residues were found to be conserved specifically in the neutral cellulases in these homologous regions.

\section{Discussion}

A gene for alkaline cellulase from Bacillus sp. KSM-635 was cloned and its nucleotide sequence was determined. In the $3498 \mathrm{bp}$ sequence there was only one ORF, beginning with an ATG initiation codon (nucleotide 1) and ending with a TAA stop codon (nucleotide 2824).

Upstream from the initiation codon of the ORF, two putative ribosome-binding sites were found, one beginning at nucleotide -65 , AAGGAGG (SD1), and another beginning at nucleotide - 10, GGAGGT (SD2). Free energies of binding $(\Delta G)$ of SD1 and SD2 were calculated to be $-17.8 \mathrm{kcal} \mathrm{mol}^{-1}(1 \mathrm{kcal} \approx 4.2 \mathrm{~kJ})$ and $-16.6 \mathrm{kcal} \mathrm{mol}^{-1}$, respectively (Tinoco et al., 1973), if they were to bind to the $3^{\prime}$ end of the 16S rRNA from $B$. subtilis. The SD1 sequence was more highly complementary to the 16S rRNA, but it was 68 nucleotides away from the ATG initiation codon of the ORF. Immediately downstream from the SD1, there was no ATG, TTG or
GTG codon, any of which would be a plausible initiation codon in such a bacterium (Gold et al., 1981). The $\Delta G$ value of the SD2 sequence and the distance of five nucleotides between the SD2 and the ATG are in reasonable agreement with data for other ribosomebinding sites reported for Bacillus strains (Hager \& Rabinowitz, 1985). Hence, the SD2-ATG sequence is the probable site of initiation of transcription of the cellulase gene in Bacillus sp. KSM-635.

The sequences TAGACG and TATTAT, found at nucleotides -134 to -106 , were highly homologous to the -35 region and -10 region, respectively, of the $\sigma^{43}$. type vegetative promoter of $B$. subtilis (Moran et al., 1982). There were 17 nucleotides between these sequences, with an AT-rich region, which is common to the $\sigma^{43}$-type promoter. In a preliminary experiment, the $A s n I-N s p(7524)$ V (nucleotides -233 to -90 ) fragment (Fig. 3) has been cloned into the promoter-selection vector pKK232-8 (Brosius, 1984), which encodes the structural gene for chloramphenicol acetyltransferase. E. coli $\mathrm{HB} 101$ transformed by pKK232-8 containing the $A s n I-N s p(7524)$ V fragment acquired resistance to chloramphenicol. A $\sigma^{43}$-type promoter sequence immediately upstream from the site of initiation of transcription of the endo-1,4- $\beta$-glucanase gene of $B$. subtilis DLG (Robson \& 
Chambliss, 1987) has been found. Consensus-like sequences of the $\sigma^{43}$-type promoter have also been reported for some cellulase genes from B. subtilis (MacKay et al., 1986; Nakamura et al., 1987; Seo et al., 1986). With respect to genes for alkaline cellulase in alkalophilic strains of Bacillus, no definitive sequence that might serve as a promoter of transcription has so far been observed.

The inverted-repeat sequence from nucleotide 2837 to 2861 had a calculated $\Delta G$ of $-13.6 \mathrm{kcal} \mathrm{mol}^{-1}$ for the stem-loop structure. There was neither a poly(T) segment immediately downstream from the stem-loop structure nor a GC-rich segment in the stem, both of which are characteristics of a $\rho$-independent terminator (Adhya $\&$ Gottesman, 1978). Recently, the $\rho$ factor that regulates the termination of transcription was found in $B$. subtilis (Hwang \& Doi, 1980). The inverted-repeat sequence may act as a $\rho$-dependent terminator of transcription of the cellulase gene in Bacillus sp. KSM-635. Another inverted-repeat sequence $\left(\Delta G=-14.0 \mathrm{kcal} \mathrm{mol}^{-1}\right)$ with a GC-rich segment and an adjacent, short, T-rich segment was observed upstream from the promoter region of the cellulase gene (from nucleotide -258 to -245 ); it may be a $\rho$-independent terminator of an unidentified gene.

From the nucleotide sequence determined, an amino acid sequence of the alkaline cellulase from Bacillus $\mathrm{sp}$. KSM-635 was deduced. The complete gene encoded the enzyme of 941 amino acid residues with a calculated molecular mass of $104626 \mathrm{Da}$. However, a carboxyterminal sequence of 357 amino acid residues seems not to be necessary for the enzymic activity, because the $2.4 \mathrm{~kb}$ fragment essential for expression of the activity does not encode this region.

The sequence from amino acids 249 to 578 , which was encoded in the $2.4 \mathrm{~kb}$ fragment, had high homology with sequences of three alkaline cellulases (Fukumori et al., $1986 a, b$ ) and four neutral cellulases (MacKay et al., 1986; Robson \& Chambliss, 1987; Nakamura et al., 1987; Zappe et al., 1988) from strains of Bacillus and Clostridium acetobutylicum P262. When the homologous sequences were suitably aligned, 90 amino acid residues were found to be conserved in all the cellulases. Some of these conserved amino acid residues may play an important role in the expression of activity of the cellulases. In particular, tryptophan residues showed a remarkably high degree of conservation, i.e. 10 of 10 or 11 tryptophan residues, in the homologous region of each cellulase, were found to be conserved. Furthermore, nine amino acid residues were conserved only in the alkaline cellulases and 18 amino acid residues were conserved only in the neutral cellulases within the regions of high homology. Some of these residues may determine the optimum $\mathrm{pH}$ for activity of the cellulases. Such amino acid residues, specific for alkaline or neutral cellulases, appear to be concentrated in the carboxy-terminal regions of the homologous amino acid sequences shown in Fig. 4. Specific amino acid residues, that were conserved only in alkaline cellulases from strains of Bacillus, have also been shown by Horikoshi \& Fukumori (1988).

A putative signal sequence in the cellulase from Bacillus sp. KSM-635 consists of a hydrophilic region of seven amino acid residues, including three lysine residues, and a hydrophobic region of 22 amino acid residues. A short, hydrophilic, basic region and a subsequent, long, hydrophobic region are characteristic of Bacillus signal peptides (Murphy et al., 1984; Mezes \& Lampen, 1985). The residues Ala-Ser-Ala, amino acids $27-29$, in the carboxy-terminal region of the hydrophobic region may be the site required for recognition by a signal peptidase (Perlman \& Halvorson, 1983).

If the signal peptide is cleaved at the carboxy-terminal of residue Ala29, the molecular mass of the mature extracellular enzyme is calculated to be $101412 \mathrm{Da}$, a value close to that of the smaller cellulase observed in the culture broth of Bacillus sp. KSM-635 (Ito et al., 1989). A larger enzyme, with a molecular mass of $300-600 \mathrm{kDa}$, as judged by gel filtration, was also observed in the culture broth, and it may represent aggregates of the smaller enzyme that is encoded by the gene identified in this study. In order to confirm a possible aggregated form of the alkaline cellulase, complete purification and characterization of the enzyme from Bacillus sp. KSM-635 are currently in progress in this laboratory.

\section{References}

Adhya, S. \& Gottesman, M. (1978). Control of transcription termination. Annual Review of Biochemistry 47, 967-996.

Ait, N., Creuzet, N. \& Forget, P. (1979). Partial purification of cellulase from Clostridium thermocellum. Journal of General Microbiology 113, 399-402.

Birnboim, H. C. \& Doly, J. (1979). A rapid alkaline extraction procedure for screening recombinant plasmid DNA. Nucleic Acids Research 7, 1513-1523.

Brosius, J. (1984). Plasmid vectors of the selection of promoters. Gene 27, 151-160.

Fukumori, F., Kudo, T. \& Horikoshi, K. (1985). Purification and properties of a cellulase from alkalophilic Bacillus sp. no. 1139. Journal of General Microbiology 131, 3339-3345.

Fukumori, F., Kudo, T., Narahashi, Y. \& Horikoshi, K. (1986a). Molecular cloning and nucleotide sequence of the alkaline cellulase gene from the alkalophilic Bacillus sp. strain 1139. Journal of General Microbiology 132, 2329-2335.

Fukumori, F., Sashihara, N., Kudo, T. \& Horikoshi, K. (1986b). Nucleotide sequences of two cellulase genes from alkalophilic Bacillus sp. strain $\mathrm{N}-4$ and their strong homology. Journal of Bacteriology 168, 479-485.

Gold, L., Pribnow, D., Schneider, T., Shinedling, S., Singer, B. S. \& Stormo, G. (1981). Translational initiation in prokaryotes. Annual Review of Microbiology 35, 365-403. 
HAGER, P. J. \& RABINOWITZ, J. C. (1985). Translational specificity in Bacillus subtilis. In The Molecular Biology of the Bacilli, vol. II, pp. 1-32. Edited by D. A. Dubnau. Orlando: Academic Press.

HORIKOSHI, K. \& FUKUMORI, F. (1988). Modification and expression of alkaline cellulase genes of alkalophilic Bacillus strains. In Biochemistry and Genetics of Cellulose Degradation, pp. 203-217. Edited by J.-P. Aubert, P. Beguin \& J. Millet. Orlando: Academic Press.

horikoshi, K., Nakao, M., Kurono, Y. \& Sashihara, N. (1984). Cellulases of an alkalophilic Bacillus strain isolated from soil. Canadian Journal of Microbiology 30, 774-779.

HWANG, J.-Y. \& DoI, R. H. (1980). Transcription-termination factor rho from Bacillus subtilis. European Journal of Biochemistry 104, 313320.

Ito, S., Shikata, S., Ozaki, K., Kawai, S., OKamoto, K., Inoue, S., TAKeI, A., OHTA, Y. \& SaTOH, T. (1989). Alkaline cellulase for laundry detergents: production by Bacillus sp. KSM-635 and enzymatic properties. Agricultural and Biological Chemistry 53, 12751281.

Kawai, S., Oxoshi, H., Ozaxi, K., Shixata, S., Ara, K. \& Ito, S. (1988). Neutrophilic Bacillus strain, KSM-522, that produces an alkaline carboxymethyl cellulase. Agricultural and Biological Chemistry 52, 1425-1431.

Langsford, M. L., Gilkes, N. R., Wakarchuk, W. W., Kilburn, D. G., Miller, R. C., JR \& Warren, R. A. J. (1984). The cellulase system of Cellulomonas fimi. Journal of General Microbiology 130, 1367-1376.

MacKay, R. M., Lo, A., Willick, G., ZuKer, M., Baird, S., Dove, M., Moranelli, F. \& Seligy, V. (1986). Structure of a Bacillus subtilis endo- $\beta$-1,4-glucanase gene. Nucleic Acids Research 14, 9159 9170.

Mandels, M. \& HigA, A. (1970). Calcium-dependent bacteriophage DNA infection. Journal of Molecular Biology 53, 159-162.

Messing, J. (1983). New M13 vectors for cloning. Methods in Enzymology 101, 20-78.

MEzes, P. S. F. \& LAMPEN, J. O. (1985). Secretion of proteins by bacilli. In The Molecular Biology of the Bacilli, vol. II, pp. 151-183. Edited by D. A. Dubnau. Orlando: Academic Press.

Miller, J. H. (1972). Experiments in Molecular Genetics. Cold Spring Harbor, NY: Cold Spring Harbor Laboratory.

Moran, C. P., JR, Lang, N., LeGrice, S. F. J., Lee, G., Stephens, M., Sonenshein, A. L., Pero, J. \& Losick, R. (1982). Nucleotide sequences that signal the initiation of transcription and translation in Bacillus subtilis. Molecular and General Genetics 186, 339-346.

MURPHY,N., MCCONNELL, D. J. \& CANTWELl, B. A. (1984). The DNA sequence of the gene and genetic control sites for the excreted $B$. subtilis enzyme $\beta$-glucanase. Nucleic Acids Research 12, 5355-5367.

NaKamura, A., Uozumi, T. \& BePPU, T. (1987). Nucleotide sequence of a cellulase gene of Bacillus subtilis. European Journal of Biochemistry 164, 317-320.
Perlman, D. \& Halvorson, H. O. (1983). A putative signal peptidase recognition site and sequence in eukaryotic and prokaryotic signal peptides. Journal of Molecular Biology 167, 391-409.

PrIEST, F. (1977). Extracellular enzyme synthesis in the genus Bacillus. Bacteriological Reviews 41, 711-753.

Rigby, P. W., J., Dieckmann, M., Rhodes, C. \& Berg, P. (1977). Labeling deoxyribonucleic acid to high specific activity in vitro by nick translation with DNA polymerase I. Journal of Molecular Biology 113, 237-251.

Robson, L. M. \& Chambliss, G. H. (1987). Endo- $\beta$-1,4-glucanase gene of Bacillus subtilis DLG. Journal of Bacteriology 169, 2017-2025.

RYU, D. D. Y. \& MANDELS, M. (1980). Cellulases: biosynthesis and applications. Enzynie and Microbial Technology 2, 91-102.

SAITo, H. \& MiURA, K. (1963). Preparation of transforming deoxyribonucleic acid by phenol treatment. Biochimica et Biophysica Acta 72, 619-629.

SANGer, F., Nicklen, S. \& Coulson, A. R. (1977). DNA sequencing with chain-terminating inhibitors. Proceedings of the National Academy of Sciences of the United States of America 74, 5463-5467.

SCHELlHORN, H. E. \& ForsBerg, C. W. (1984). Multiplicity of extracellular $\beta$-(1,4)-endoglucanases of Bacteroides succinogenes S85. Canadian Journal of Microbiology 30, 930-937.

Seo, Y. S., Lee, Y. H., PeK, U. H. \& Kang, H. S. (1986). Analysis on the nucleotide sequence of the signal region of Bacillus subtilis extracellular cellulase gene. Korean' Journal of Microbiology 24, 236242

Teather, R. M. \& Wood, P. J. (1982). Use of Congo redpolysaccharide interactions in enumeration and characterization of cellulolytic bacteria from the bovine rumen. Applied and Environmental Microbiology 43, 777-780.

Tinoco, I., JR, Borer, P. N., Dengler, B., LeVine, M. D., Uhlenbeck, O. C., Crothers, D. M. \& Gralla, J. (1973). Improved estimation of secondary structure in ribonucleic acids. Nature New Biology 246, 40-41.

Yoshikawa, T., SuzukI, H. \& Nisizawa, K. (1974). Biogenesis of multiple cellulase components of Pseudomonas fluorescens var. cellulosa. I. Effects of culture conditions on the multiplicity of cellulase. Journal of Biochemistry 75, 531-540.

WoOD, T. M., Wilson, C. A. \& Stewart, C. S. (1982). Preparation of the cellulase from the cellulolytic anaerobic rumen bacterium Ruminococcus albus and its release from the bacterial cell wall. Biochemical Journal 205, 129-137.

ZAPPE, H., Jones, W. A., Jones, D. T. \& WoOds, D. R. (1988). Structure of an endo- $\beta$-1,4-glucanase gene from Clostridium acetobutylicum P262 showing homology with endoglucanase genes from Bacillus spp. Applied and Environmental Microbiology 54, 1289-1292. 